\title{
TELAAH KITAB TAFSIR ATH-THABARI DALAM Q.S AL-MAIDAH AYAT 51
}

\author{
Adistia, Yusril \\ Nur Baitul Izzah, Nikmah, \\ Muhammad afif \\ Email : \\ Ilmualqurantafsir2019@gmail.com / iat@iainpalu.ac.id
}

\begin{abstract}
Abstrak.
Artikel ini ingin menjelaskan kepada pembaca mengenai penafsiran Kitab Tafsir al-Tabari yang dibuat sendiri oleh Imam Al-Tabari. Dalam penjelasannya penulis akan menjelaskan profil, metodologi dan salah satu contoh penafsirannya disertai sistemtika penulisannya. Dalam menjelaskan telaah kitab Tafsir ini penulis menggunakan metode library research artinya studi kepustakaan. Untuk menjelaskan penafsirannya penulis mengamnil sampel penafsiran al-Tabari dalam Q.S al-Maidah ayat 51. Penulis akan mengemabil kajian dari berbagai buku-buku atau referensi yang berhubungan dengan. Al-Tabari adalah seorang mufassir yang digolongkan sebagai mufasir senior, dan karyanya sampai saat ini masih dijadikan rujukan oleh banyak orang terkait penafsiran Al-Qur'ān. Adapun karya monumental al-Thabari adalah Tafsir al-Tabari. Kitab Tafsirnya berjudul Jami $\bar{i}^{‘}$ al-bayān ‘an Ta’wil Ayyil Qur'an.
\end{abstract}

Kata kunci: Al-Qūran, al-Tabari, dan Penafsiran 
Volume 1, Number 2, Desember 2019: 55 - 78

Abstract

This article would like to explain to the reader about the interpretation of the Book of Tafsir al-Tabari made by Imam AlTabari. In its explanation the author will explain the profile, methodology and one example of its interpretation accompanied by a systemic writing. In explaining the study of the book of Tafsir, the writer uses the library research method, which means the study of literature. To explain the interpretation the author took a sample interpretation of al-Tabari in Q.S al-Maidah verse 51. The author will take study of various books or references relating to. Al-Tabari is a commentator who is classified as a senior commentator, and his work is still used as a reference by many people regarding the interpretation of the Qur'an. The monumental work of al-Tabari is Tafsir al-Tabari, the title is Jami 'al-bayān' an Ta’wil Ayyil Qur'an. 


\section{Pendahuluan}

Al-Qur'ān adalah kitab suci yang diturunkan oleh Allah 彞 kepada nabi Muhammad yang berisikan petunjuk atau informasi yang terdapat didalam setiap ayat atau surat. Di dalam Al-Qur'ān surat Al-Maidah: 51 berisi tentang larangan umat Muslim dan memilih dan mengangkat seorang Nasrani dan Yahudi menjadi Awliyāă. Terdapat banyak ragam arti Awliyā', di dalam AlQur'ān, Awliyā' yang terdapat di dalam Al-Qur'ān sebuah kata yang memiliki banyak arti, kata Awliyā' di dalam Al-Qur'ān disebutkan sebanyak 42 kali, mencakup 40 ayat, yang tersebar dalam 23 surah termasuk di dalam surah Al-Maidah: 51. ${ }^{1}$

Kata Awliyā' diterjemahkan didalam bahasa indonesia berarti pemimpin-pemimpin. Meskipun demikian jika kita melihat tafsīr al-Misbah karya Quraish Shihab kata Awliyā’’ berarti sesuatu yang dekat. Perbedaan penafsiran ini bisa dilihat di dalam beberapa kitab-kitab tafsir lainnya. ${ }^{2}$

${ }^{1}$ Dani M. Habibi, Penafsiran Al-Qur'ān Surat Al-Maidah Ayat 51. (Yogyakarta: 2017) h. 1

${ }^{2}$ Hamka, Tafsir Al-Azhar (Malaysia: Pustaka Islamiyah, 2007). H. 1762. Di lihat juga di dalam tafsï Muhammad Nasib ar-Rifa'i, Ringkasan Tafsir Ibn Katsir, (Jakarta: Gema Insani, 2012) h. 80-81. Sayyid Quthb, Tafsir Fi Zhilail Qur'an di Bawah Naungan Al-Qur'ān, (Jakarta: Gema Insani, 2002) h. 249. Syaikh Asy-Syanqithi, Tafsìr Adhwa'ul Bayan Tafsir Al-Qur'ān dengan Al-Qur'ān , (Jakarta: Pustaka Azzam, 2007) h. 157-159. Imam Asy-Syaukani, Tafsir Fathul Qadir, (Jakarta: Pustaka Azzam, 2009) h. 413-415. 
Dalam menafsirkan Al-Qur'ān tentunya tidak terlepas dari teks dan konteks. Di mana setiap penafsiran mempunyai pandangan-pandangan yang berbeda. Hal ini tidak lain adalah dilatarbelakangi oleh kepentingan para mufasir itu sendiri. Perbedaan penafsiran atau pandangan para ulama di dalam memahami surah al-Maidah: 51 ternyata dapat menjadikan sebuah konflik di antara para ulama dalam soal menafsirkan, seperti kasus yang menimpa Basuki Tjahaja Purnama atau biasa disebut Ahok, didalam pidatonya di Puluan Seribu dengan kasus Penistaan Agama. ${ }^{3}$ Karena ayat tersebut merupaka ayat yang muncul pada waktu dan tempat tertentu yang mempunyai history dalam kemunculannya. Jika kita diperhatikan ayat tersebut berbicara tentang bagaimana larangan dalam meimilih seorang pemimpin non muslim. Secara history ayat tersebut berbicara tentang kisah yang diriwayatkan oleh $\mathrm{Abu}$ Lubabah tentang orang-orang munafik yang membongkar rahasia-rahasia kaum muslim kepada orang-orang musyrik. Riwayat lain berbicara tentang perang uhud ketika kaum muslim di hadapi dengan perasaan ketakutan sehingga mereka berniat untuk menjadikan orang-orang Yahudi dan Nasrani sebagai seorang pemimpin ${ }^{4}$

${ }^{3}$ Habibi, Penafsiran Al-Qur'ān Surat Al-Maidah Ayat 51. h. 1

${ }^{4}$ Syeh Imam Al-Qurthubi, Tafsir Al-Qur'ān Tafsir Al-Qurthubi (Jakarta: Pustaka Azzam, 2009) Jilid 6,Cet. 1, h. 519 


\section{Profil Mufassir}

Nama lengkap at-Thabari adalah Abu Ja'far Muhammad bin Jarir bin Yazid bin Katsir bin Ghalib at-Thabari. Ia di lahirkan pada tahun 224-5 H/839 M di kota Amul ibu kota Thabaristan, wilayah propinsi Mazandran, Iran. ${ }^{5}$ Ibn Jarir at-Thabari adalah seorang yang sangat ahli dalam fiqih. Beliau adalah pendiri mazhab, tetapi sangat disayangkan tidak ada yang mengumpulkan pendapat beliau untuk menjadikan sebuah mazhab fiqih. Ibn Jarir at-Thabari juga adalah seorang pakar sejarah, beliau mempunyai karangan kitab sejarah yang sangat populer. Beliau juga seorang pakar hadits, beliau satu-satunya figur yang tidak ada duanya. ${ }^{6}$

At-Thabari sangat dikenal sebagai ulama yang mampu menghafal Al-Qur'ān sekaligus memahami maksud dan maknanya, faqih dalam bidang hukum, menguasai as-Sunnah baik dalam hal shahih-saqim-nya maupun nasikh-mansukh-nya, bahkan aqwal asShahabah wa at-Tabi'in juga ia kuasai. Di samping itu, ia juga menguasai tentang sejarah manusia. ${ }^{7}$ Selain dikenal sebagai ulama yang 'alim 'allamah, at-Thabari juga sangat mashsyur dengan ke zuhudan-nya.

${ }^{5}$ Shohibul Adib,M Syihabuddin Muin,Fahmi Arif El Muniry, Ulumul Qur'an Ptrofil Para Mufassir Al-Qur'ān dan Para Pengkajinya. (Banten: Pustaka Dunia, 2011), h. 1

${ }^{6}$ Mahmud, Mani' Abd H.im, Metodologi Tafsir Kajian Komprehensif Metode Para Ahli Tafsir. (Jakarta: PT RajaGrafindo Persada, 2006) h. 67

${ }^{7}$ Muhammad Husean ad-Dzahabi, at-Tafsir wa al-Mufassirun, vol. I (Kairo: Maktabah Wahbah, 1995) h. 215 
Volume 1, Number 2, Desember 2019: 55 - 78

Usia 12 tahun $(236 \mathrm{H})$, at-Thabari memulai perjalanan intelektualnya, menuntut ilmu dengan mengembara ke luar dari negaranya. Negara-negara yang pernah ia singgahi antara lain: Mesir, Syam, dan Iraq. Setelah sekian lama melakukan penembaraan intelektualnya di beberapa negara, ia menghabiskan masa hidupnya di negeri Iraq tepatnya di kota Baghdad hingga wafatnya pada tahun $310 \mathrm{H} / 923 \mathrm{M}^{8}$ Domisili terakhir sepulang dari Mesir adalah Baghdad dan sempat singgah di Tabaristan. Adapun pada permulaan tinggal di Baghdad ia bermazhab Syafi'fi kemudian dengan kecerdasannya beliau berlepas dan berijtihad sendiri. Pada akhir pergulatan pemikirannya, ia lebih dikenal luas sebagai seorang Sunni ketimbang seorang Rafidi-ektemis Ali yang pernah hangat diributkan oleh para ulama sezamannya ketika memuncaknya aliran-aliran teologi. Bukti bahwa ia adalah seorang sunni terlihat dalam karya-karyanya di bidang sejarah dan tafsï. ${ }^{9}$

\section{Profil Kitab Tafsir}

Mengenai karya-karya at-Thabari, Ibn Katsir telah menuturkan, bahwa at-Thabari telah melakukan aktifitas menulis selama kurang lebih 40 (empat puluh) tahun yang setiap harinya mencapai 40 (empat puluh) halaman. ${ }^{10}$ Karna itu tidak mustahil karya-karyanya sangat banyak. Ia menulis beberapa buku dalam

${ }^{8}$ Al-Dzahābi, at-Tafsìr wa al-Mufassirun, vol. I, h. 215

9 Chonyta, Didin, Jamī' Al-bayān Fi Tafsìr Al-Qur'ān

10 Lihat Ibn Katsir, Al-Bidayah Wa An-Nihayah, vol 10 h. 342 dalam CD rom, Maktabah Al-Hadits As-Syarif, 1999 
beberapa bidang keilmuan yang sangat mengagumkan. Di antara banyaknya kitab at-Thabari, yang paling terkenal adalah kitab dengan nama Jamī' al-bayān fì Tafsìr Al-Qur'ān atau yang sering disebut dengan Tafsir at-Thabari. ${ }^{11}$ Tetapi kitab tafsir karya atThabari memiliki nama ganda yang dapat dijumpai di berbagai perpustakaan; pertama, Jamī' al-bayān An Ta'wil Ay Al-Qur'ān dan Tafsìr Jamī al-bayān Fi Tafsìr Al-Qur'ān ${ }^{12}$

Jamī' al-bayān fi Tafsìr Al-Qur'ān dicetak di Beirut dari penerbit Dar al-Kutub al-'Ilmiyyah tahun 1992, dan Jamī' albayān An Ta'wil Ay Al-Qur'ān dicetak di Beirut dari penerbit Dar al-Fikr tahun 1995 dan 1998. Sistematika penafsiran at-Thabari mengikuti tartib mushafi. Yakni mufasir menguraikan penafsirannya berdasarkan urutan ayat dan surah di dalam mushaf (utsmani). Sekalipun demikian, pada beberapa bagian tertentu, ia juga menggunakan pendekatan yang semi-tematis. Pendekatan ini terlihat ketika menguraikan penafsiran suatu ayat dengan memberikan sejumlah ayat-ayat lain yang berhubungan sebagai penguat penafsirannya. Namun, secara umum ia tidak keluar dari sistematika mushaf Utsmani). ${ }^{13}$ Kitab tafsir ini ditulis oleh atThabari pada paruh abad III H, dan sempat disosialisasikan di

${ }^{11}$ Shohibul Adib,M Syihabuddin Muin,Fahmi Arif El Muniry, Ulumul Qur'an Ptrofil Para Mufassir Al-Qur'ān dan Para Pengkajinya. (Banten: Pustaka Dunia, 2011) h. 1

${ }^{12}$ Al-Tabari, Jamī' Al-bayān Fi Tafsìr Al-Qur’ān, h. 45

${ }^{13}$ Al-Tabari. Jamī 'Al-bayān Fi Tafsìr Al-Qur’ān, h. 46 
Volume 1, Number 2, Desember 2019: 55 - 78

depan para muridnya selama kurang lebih 8 tahun, sekitar 282 hingga $290 \mathrm{H}^{14}$

Metode tafsīr yang di gunakaan oleh at-Thabari menurut H. Abdul Djalal, metode muqaran (komparatif) digunakan dalam tafsïr ini. Karena di dalamnya memuat pendapat-pendapat ulama dan membandingkan pendapat sebagian mereka dengan pendapat sebagian yang lain. ${ }^{15}$

Namun yang paling disayangkan adalah dari sekian banyak karya at-Thabari, sebagian besar hilang dari peredaran, seiring dengan rentang waktu dan perjalanan yang sangat panjang hingga sampai sekarang. ${ }^{16}$ tafsīir at-Thabari di kenal dengan tafsīir bi alMa'tsur, yang mendasarkan penafsirannya pada riwayat-riwayat yang bersumber dari Nabi 䌙, para sahabatnya, tabi'in. Dan tabi'ut tabi'in. $^{17}$

Beberapa keistimewaan tafsīr ini. Pertama, Berpegang pada atsar berupa Hadis (ucapan Nabi), Sahabat dan Tabi'in. Kedua, Senantiasa menyebutkan sanad dan pendapat yang diriwayatkan serta mentarjihan dari riwayat yang di kemukakanya. Ketiga, Memaparkan ayat-ayat yang nasikh dan mansukh serta menjelaskan tentang riwayat yang shahih dan yang

\footnotetext{
${ }^{14}$ Al-Tabari, Jamī' Al-bayān Fi Tafsìr Al-Qur'ān, h.130

${ }^{15}$ H. Abdul Djalal, Ulumul Qur'an, (Surabaya: Dunia Ilmu, 2002) h. 31

${ }^{16}$ Muhammad Husean ad-Dzahabi, at-Tafsir wa al-Mufassirun, vol. I (Kairo: Maktabah Wahbah, 1995) h. 216

${ }^{17}$ Al-Tabari, Didin, Jamī ‘ Al-bayān Fi Tafsìr Al-Qur’ān, h. 123
} 
dhaif. Dan Yang Keempat, Menyebutkan segi I'rob (uraian kalimat) dan pengistimbatan hukum syari'at dari ayat-ayat AlQur'ān. $^{18}$

Para ulama sangat banyak membicarakan tentang beliau, baik dari kepribadian maupun kehidupan beliau yang ditinjau dari berbagai sisi sudut pandang. Al-Khatib berkata: "Ibn Jarir atThabari adalah salah satu imam dan pemimpin umat, perkataanya dapat dijadikan hukum dan pendapatnya dapat dijadikan rujukan. Beliau adalah seorang hafiz (hafal) Al-Qur'ān, mengetahui makna ayat-ayatnya serta paham dan mengenal hukum-hukum Al-Qur'ān. Beliau mengetahui sunah-sunah baik dari segi perawinya maupun kedudukannya baik shahih ataupun tidak, nasakh atau mansukh beliau juga mengetahui perkataan para sahabat dan tabi'in serta ulama penerusnya. Beliau juga mengetahui tentang masalah yang diharamkan dan yang dihalalkan. Selain itu beliau juga tau tentang sejarah dan kisah masa lalu."19

Abu al-Abbas bin Juraij berkata : " Muhammad bin jarir adalah seorang fiqih yang alim”. Dalam tafsìr beliau terlihat beberapa kelebihan anatar lain (1) kehati-hatian beliau dalam mengarang; (2) kerajianan beliau dalam mempersiapkan ; (3)kegembiraan ketik sudah selesai. Para ahli sejarah mengatakan

${ }^{18}$ Mohammad Aly Ash Shabuny/ Pengantar study Al-Qur'ān : bandung, pt al ma'rif 1996 h. 258

${ }^{19}$ Mahmud, Mani' abd Halim, Metodologi Tafsïr Kajian Komprehensif Metode Para Ahli Tafsir ( Jakarta, Pt Raja Grafindo Persada, 2006), h. 69-70 
Volume 1, Number 2, Desember 2019: 55 - 78

bahwa Ibn Jarir at-Thabari sudah menyebutkan tafsīr seperti ini padahal beliau masih kecil, keudian beliau beristikharah kepada Allah swt. Agar dia bisa membukukan tafsīr yang beliau miliki. ${ }^{20}$

Dalam sebuah buku ${ }^{21}$ tersebut terdapat puji-pujian kepada Allah 静 Dan shalawat kepada Rasul Allah. Setelah itu beliau berkata "Sesungguhnya keutamaan yang lebih besar dan kemuliaan yang paling agung diberikan Allah 感 kepada umat Nabi Muhammad dan ang dilebihkan Allah 此 terhadap umat-umat sebelumnya dengan kedudukan dan martabat yang lebih tinggi, dan diberikan kecintaan kepada sunnah-sunnah nabi-Nya adalah dengan menjaga atau memelihara wahyu yang diturunkan kepada Nabi Muhammad Wahyu atau Al-Quran yang menjadi dalil kebenaran Rasulullah Wahyu yang diturunkan sebagai tanda yang paling jelas akan kebenaran Rasulullah 縴. Dan sebagai hujjah yang lengkap terhadap mereka yang mendustakan dan mereka yang membangkang. Wahyu yang menjelaskan antara kafir dan musyrik. Wahyu yang menentang mereka baik dari golongan jin maupun manusia untuk mendatangkan seumpama wahyu dan mereka mereka tidak mampu melakukannya walaupun mereka saling tolong menolong. Wahyu yang dapat membuat yang gelap

${ }^{20}$ Mahmud, Metodologi Tafsïr Kajian Komprehensif Metode Para Ahli Tafsir: h. 69-70.

${ }^{21}$ Mahmud, Metodologi Tafsir Kajian Komprehensif Metode Para Ahli Tafsir h.72-77. 
gulita menjadi terang menderang. Wahyu yang memberikan terang dalam kegelapan yang dapat menutun orang-orang kepada hidayah dan jalan yang benar serta keselamatan.

Allah 鉴 memeliharanya dengan penglihatan mata yang tidak pernah tidur dan meliputi sekelilingnya tanpa menghilangkan sedikit pun. Pengikutinya tidak akan ditentang dan sahabatnya tidak akan di sesatkan. Barang siapa mengikutinya niscaya akan beruntung dan mendapat hidayah dan barangsiapa yang menentang maka akan sesat dan binasa. Dia adalah wahyu tempat berlindung yang bisa menolong manusia ketika mereka berselisih pendapat dan dapat memberikan bimbingan terhadap akal mereka kepada berpikir yang benar. Wahyu juga mejelaskan kepada mereka haknya atas mereka, juga menjeskan keridhaan mereka dan menjelaskan bahwa wajib berpegang teguh dengannya agar mereka mendapatkan apa yang mereka inginkan, yaitu terpelihara dari kebinasaan.

Ibn Jarir at-Thabari juga berbicara masalah perkara penting dalam Al-Qur'ān yang berhubungan dengan penafsiran beliau. Misalnya, beliau berbicara tentang kerapian makna-makna ayatayat Al-Qur'ān yang tersusun dan makna-makna logika terhadap hamba yang diturunkan kepadanya Al-Qur'ān. Kemudian beliau menjelaskan tentang huruf-huruf Al-Qur'ān yang sama penuturannya dengan bahasa-bahasa lain dan menjelaskan hurufhuruf yang berbeda dengan bahasa lain. Kemudian beliau berbicara 
Volume 1, Number 2, Desember 2019: 55 - 78

masalah bahasa-bahasa Al-Qur'ān yang mana diturunkan dengan bahasa arab yang bermacam-macam. Kemudian beliau menyebutkan beberapa riwayat yang melarang penta'wilan dengan menggunakan akal pikiran semata.

Beliau menyebutkan sebagan ulama tafsīr terdahulu, di antara mereka ada yang terpuji dan tidak terpuji. Di antara mereka yag terpuji dalam menafsirkan Al-Qur'ān adalah Ibn Abbas r.a. Di antara mereka yang terpuji lainnya adalah Mujahid. Adapun di antara mereka yang tidak mendatangkan penafsiran secara mahir adalah al-Kalabi (Aku pernah disuruh mendatanginya sesat waktu siang dan aku tidak menulis dari dia). Di antara mereka yang lain adalah Abu Shaleh Badzan. Al-Sya'abi pernah berjalan melewati Abu Shaleh kemudian al-Sya'abi memegang kupingnya dan menjewer telinganya sambil berkata: "Kamu menafsirkan AlQur'ān, padadal kamu tidak membacanya."

Kemudian beliau menyebutkan penjelasan terhadap namanama Al-Qur'ān, nama-nama surah dan nama-nama ayat. Setelah semua itu barulah pindah kepada penafsiran ayat-ayat Al-Qur'ān. Dalam menafsirkan beliau mengemukakan pendapatnya dengan berlandaskan pada riwayat atsar dan khabar serta ucapan dan kaidah-kaidah ulama terdahulu.

Kitab At-Thabari, berhak mendapat pujian dari para ulama. Ibnu Khuzaimah berkata "Aku telah memperhatikan kitab ini dari 
awal sampai akhir, sungguh tidak ada yang lebih alim dari muka bumi ini melainkan Muhammad bin Jarir. Sungguh para ulama Hambali telah berbuat zalim kepadanya."

Imam Suyuthi berkata: "Karangan Ibn Jarir At-Thabari adalah kitab tafsir yang paling mulia dn terebesar, kitab tersebut mengemukakan pendapat-pendapat para ulama dan menyatakan salah sau pendapat yang paling rajih. Kitab ini juga mengemukakan i'rab dan istinbat ayat. Ini adalah kitab tafsir yang lebih tinggi di bandingkan kitab-kitab tafsīr sebelumnya."

\section{Penafsiran Mufassir Terhadap Ayat Tersebut}

Berkata Abu Ja'far :Para ahli ta'wil berbeda dalam menanggapi masalah makna dalam masalah ini. Meskipun mereka adalah orang-orang yang diperintahkan kepada seluruh orangorang mukmin. Sebagian dari mereka berkata saya termasuk, mengenai hal itu Ubadah bin Shomat dan Abdullah bin Abi Salul berlepas diri dalam beribadah, bersumpah kepada orang-orang Yahudi. Dan di dalam bersekutu Abdullah bin Abi Salul dengan sumpah orang-orang Yahudi, setelah ap yang nampak dari padanya, perlawanan atau permusuhan mereka kepada Allah dan Rasulullah. Dan Allah memberikan kabar kepada mereka bahwasanya berpaling dari mereka dan bersekukuh dari sumpah 
mereka, adalah termasuk dari golongan mereka,dalam hal berlepas diri dari Allah dan Rasulnya. ${ }^{22}$

Dari Abi Karib berkata kepada kami, dia berkata Ibnu Idris berkata kepada kami, dia berkata saya mendengar Ayahku tentang Atiyyah bin Sa'din berkata telah datng Ubadah bin Shomat dari Bani Harits bin Khuzdraj kepada Rasulullah, lalu ia berkata, "Wahai Rasulullah lalu Abdullah bin Abi berkata, sesungguhnya saya seorang pemuda yang takut, giliran-giliran tidak terlepas dari wilayah kaum keluargaku. Lalu Rasulullah berkata kepada Abdullah bin Abi, Wahai Abal Habab, kenapa kamu kikir sekali terhadap hal itu, dari wilayah Yahudi terhadap Ubadah bin Shomat dia bersama tanpanya. Dia berkata "Saya telah menerimanya,dan turunlah ayat."23

Berkata kepada kami Hanad, dia berkata : berkata kepada kami Yunus bin Bakir, ia berkata kepadaku, Utsman bin Abdurrahman dari Zuhri, ia berkata, "Kenapa orang-orang (badar) ditaklukkan?, orang-orang Yahudi berkata "orang-orang muslim dilindungi orang-orang Yahudi mereka yang mana mereka telah beriman sebelum Allah memberi kalian musibah pada hari ini, seperti perang badar. Malik Shoib berkata "Mereka menipui

22 Abi Ja'far Muhammad bin Jarir at-Thabari, Jamì' Al-Bayān An Ta'wìili Ay Al-Qur'ān. Jilid 8 h. 504

${ }^{23}$ Muhammad bin Ismail al-Bukhari, Sahīh al-Bukhāri, Jilid 3, (Kairo: Dār al-Hadith, 2005), h. 45. 
kalian, bahwa kalian akan ditimpa musibah, kelompok dari kaum Quraisy, yang tidak mengajari kalian berperang."

Menceritakan kepada kami Abu Karib, menceritakan kepada kami Yunus bin Bakir, dari Muhammad bin Ishak, menceritakan kepadaku Muhammad bin Abi Muhammad Maula Zaid bin Sabit. berkata, menceritakan kepadaku Za'id bin Jabir atau Ikrimah, dari Ibnu Abbas. Berkata, Ka'ab bin Asad dan Ibnu suriyah dan Sya'su bin Qish dari sebagian yang lain. Bawalah kami kepada Muhammad, Agar kami memfitnah terhadap agamanya kemudian mereka mendatangi Rasulullah dan berkata, wahai muhammad engkau sungguh telah mengetahui bahwa saya adalah pembesar Yahudi yang paling mulia dan tempat mereka bersandar atau mengadu dan saya mengikutimu dan saya pun mengikuti oran-orang Yahudi dan mereka pun tida setuju denganMu karena kami dan kaumMu saling bermusuhan. Maka putuskanlah untuk kami/hakimilah kami dan berikanlah keputusan kepada kami agar kami meyakinimu dan membenarkanmu. Namum Rasulullah enggan. Kemudian Allah menurunkan ayatnya "dan hendaklah kamu memutuskan perkara diantara mereka menurut apa yang diturunkan oleh Allah. Dan janganlah kamu mengikuti hawa nafsu mereka dan berhati-hatilah kamu terhadap mereka supaya tidak memalingkanmu dari sebagian apa yang diturunkan Allah kepadamu, jika mereka berpaling dari hukum yan diturunkan Allah. Maka ketahuilah bahwa sesungguhya Allah 
Volume 1, Number 2, Desember 2019: 55 - 78

menghendaki agar menimpakan musibah/Adzab kepada mereka. Dan sesungguhnya kebanyakan manusia adalah oran-orangyang fasik." Apakah hukum jahiliyah yang mereka hendaki/inginkan siapa yang paling baik, hukumnya dari pada hukum Allah bagi orang-orang yang menghakiminya. ${ }^{24}$

Telah diceritakan kepadaku dari Yunus, ia berkata, telah mengabarkan kepada kami Ibnu Wa'hab, dia berkata, telah berkata Ibnu Zaid pada Firman Allah yaitu "maka berhati-hatilah kamu terhadap mereka supaya mereka tidak memalingkan kamu dari sebahagian apa yang telah diturunkan Allah kepadamu”. Bahwasanya mereka mengatakan dalam kitab Taurat dengan perkataan yang serupa dan sungguh telah kami tunjukkan/jelaskan kepadamu apa yang tercantum/tertulis didalam kitab Taurat dan membacanya. Dan kami telah menetapkan terhadap mereka didalamnya (taurat) bahwasanya jiwa dibalas dengan jiwa, mata dibalas dengan mata, hidung dengan hidung, telinga dengan telinga, gigi dengan gigi, dan luka-luka ada Qisasnya. (Q.s AlMaidah : 45) sebagian daripada sebagiannya.

Ya'qub menceritakan kepada kami, ia berkata, menceritakan kepada kami Hasyim dari Muqirah, dari Syu'bih, ia berkata, "Telah masuk orang-orang majusi bersama orang-orang

24 Abi Ja'far Muhammad bin Jarir at-Thabari, Jamī' Al-Bayān An Ta’wìli Ay Al-Qur'ān. Jilid 8 h. 505 
ahli kitab di dalam ayat ini, "dan sungguh Allah telah memutuskan di antara kalian apa yang telah di turunkan-Nya”.

Berkata Abu Ja'far berkata, Apakah mereka (Yahudi) mengambil hukum darimu akan tetapi mereka tidak ridho dengan keputusanmu. Jika kamu memberikan keputusan tanpa pengetahuan (kebodohan). Yakni ketentuan penyembahan terhadap dan Ahli Syirik.

Dan berkata sebagian orang lain, tetapi ini tentangku dengan Abu Lubabah bin Abdan Mundzir pada pengetahuannya Bani Quraidzah dengan Ridhonya mengambil hukum (Bani Sa'id) ${ }^{25}$

Berkata Abu Ja'far, perkataa yang paling tepat adalah. Sesungguhnya Allah Ta'ala, mengingatkan larangan terhadap orang mu'min pada umumnya. Menjadikan orang-orang Yahudi dan Nasrani sebagai penolong. Dan menjadikan sekutu terhadap orang yang beriman kepada Allah Rasulnya, dan dikabarkan bahwasanya siapa yang menjadikan mereka tempat pertolongan, sekutu, dan pemimpin selain Allah, Rasul, dan orang-orang mukmin, maka mereka berpihak kepada Allah, dan Rasul-Nya berlepas diri darinya. ${ }^{26}$

25 Abi Ja'far Muhammad bin Jarir at-Thabari, Jamī' Al-Bayān An Ta'wïli Ay Al-Qur'ān. Jilid 8 h. 506

${ }^{26}$ at-Thabari, Jamī' Al-Bayān An Ta'wìli Ay Al-Qur'ā, h. 507 
Volume 1, Number 2, Desember 2019: 55 - 78

Adapun Firman Allah "menajadikan sebagian mereka pemimpin sebagian yang lainnya." Dalam firman Allah ini mengingatkan orang-orang mukmin maka jadilah kalian semua pemimpin (mu'min) sebagian yang lain.

Ta'wil dari firman Allah "wahai orang-orang yang beriman! Janganlah kamu menjadikan orang Yahudi dan Nasrani sebagai teman setia(mu); mereka satu sama lain saling melindungi".

Abu Ja'far berkata, yakni Allah Ta'ala berfirman "barangsiapa diantara kamu yang menjadikan mereka teman setia. Maka sesungguhnya dia termasuk golongan mereka”. Siapa yang mengangkat Yahudi dan Nasrani selain orang mu'min. Maka mereka itu termasuk dari golongan mereka (Yahudi dan Nasrani) dan berkata Ubadah. Wahai Rasululah ! pemimpinku adalah orang Yahudi dia adalah seorang yang berkepribadian keras. banyak persenjataan, kuat dalam pertahanan, dan saya sungguh telah berdosa kepada Allah dan Rasul-Nya dan berkata Abdullah bin Abi salul, "akan tetapi saya tidak merasa berdosa, saya adalah seorang laki-laki buruk dari kalangan mereka. kemudian Rasulullah berkata wahai Aba Hubab, tahukah kamu orang-orang yang serupa dengan kesetiannya terhadap Yahudi dan 
peribadatannya. maka itu ada adalah engkau dan Bukan Dia (ubadah) kemudian saya menerimanya. ${ }^{27}$

kemudian firman Allah "dan Allah hendak menjagaMu dari mereka". Perkataan dari sebagian Ahli Ta'wil, dalam firman Allah "sesungguhnya Allah tidak memberikan hidayah kepada orangorang yang dzolim". 28

Berkata Abu Ja'far. Yakni, bahwasanya Allah tidak menyetujui bagi orang yang meletakkan pemerintahan kepada yang bukan ahlinya. Maka, mendukung orang-orang Yahudi dan Nasrani termasuk Musuh Allah, Rasul, dan oran-orang mu'min karena menjadikan mereka sebagai pemimpin mereka. Itu sama saja memerangi Allah, Rasul, dan orang-orang mu'min, dan telah dijadikan makna dzolim adalah meletakkan sesuatu bukan pada tempatnya.

Perkataan sebagian Ahli Ta'wil tentang Al-maidah 52 "maka kamu akan melihat orang-orang yang hatinya berpenyakit segera mendekati mereka (Yahudi dan Nasrani) seraya berkata. kami takut akan mendapati bencana".

Berkata Abu ja'far, Ahli Ta'wil berbeda pendapat mengenai ayat ini, adapun sebagian mereka berkata yan dimaksudkan adalah Abdullah bin Abi Salul, dan orang lain

${ }^{27}$ Ibid, h. 508

28 Abi Ja'far Muhammad bin Jarir at-Thabari, Jamì' Al-Bayān An Ta’wìli Ay Al-Qur'ān. Jilid 8 h. 510 
berkata, kaum munafik/orang-orang munafik menjadikan orangorang yahudi sebagai penasehat. Dan berbuat curang terhadap orang-orang mu'min. Dan orang-orang munafik berkata, "kami takut orang-orang Yahudi menjadi bencana terhadap orang-orang mu'min.

Perkataan sebagian Ahli ta'wil dalam firman Allah "sesungguhnya Allah tidak memberikan hidayah kepada orangorang yang dzalim".

Dalam kitabnya, at-Thabari juga tidak lupa menjelaskan tafsï surat al-Maidah 51. Ia menjelaskannya panjang lebar dan mendiskusikan beberapa riwayat yang berkaitan dengan konteks penurunan ayat ini. Setelah mengutip kisah perdebatan 'Ubadah bin Shamit dan 'Abdullah bin Ubay, kisah Abu Lubabah, dan kisah dua orang muslim yang pindah agama lantaran takut ditimpa kesusahan.

\section{Kesimpulan}

Berdasarkan pemaparan yang telah di sampaikan oleh penulis tentang surah Al-Maidah ayat 51, maka dapat di ambil kesimpulan, yaitu:

Pada perkembangan makna didalam tafsir surah Al-Maidah ayat 51 ini terdapat pesan moral yaitu, mengajarkan kita berkehidupan yang baik bagi umat muslim, juga dilarangnya 
memilih pemimpin yang non muslim karena di khawatirkan akan menyebar luaskan rahasia-rahasia yang dimiliki umat muslim, juga dilarangnya umat muslim mendekati orang-orang munafik yang bisa bermuka dua saat bersama kita. 
Volume 1, Number 2, Desember 2019: 55 - 78

\section{DAFTAR PUSTAKA}

Dani M. Habibi, Penafsiran Al-Qur'ān Surat Al-Maidah Ayat 51 Yogyakarta: 2017

Hamka, Tafsir Al-Azhar. Malaysia: Pustaka Islamiyah, 2007.

Muhammad Nasib ar-Rifa'i, Ringkasan Tafsir Ibn Katsir Terjemahan. Jakarta: Gema Insani Press, 2012.

Sayyid Quthb, Tafsir Fi Zhilail Qur'an di Bawah Naungan AlQur'ān.Terjemahan. Jakarta: Gema Insani, 2002.

Syaikh Asy-Syanqithi, Tafsìr Adhwa'ul Bayan Tafsìr Al-Qur'ān dengan Al-Qur'ān. Terjemahan Jakarta: Pustaka Azzam, 2007.

Imam Asy-Syaukani, Tafsïr Fathul Qadir. Terjemahan. Jakarta: Pustaka Azzam, 2009

Syeh Imam Al-Qurthubi, Tafsìr Al-Qur'ān Tafsìr Al-Qurthubi. Terjemahan. Jakarta: Pustaka Azzam, 2009

Shohibul Adib, dkk. Ulumul Qur'an Ptrofil Para Mufassir AlQur'ān dan Para Pengkajinya. Banten: Pustaka Dunia, 2011.

Mani' Mahmud Abd Halim, Metodologi Tafsir Kajian Komprehensif Metode Para Ahli Tafsir. Terjemahan Jakarta: PT Raja Grafindo Persada, 2006.

Muhammad Husean ad-Dzahabi, at-Tafsir wa al-Mufassirun, vol. I Kairo: Maktabah Wahbah, 1995.

Ibn Katsir, Al-Bidayah Wa An-Nihayah, vol 10 hal 342 dalam CD rom, Maktabah Al-Hadits As-Syarif, 1999

H. Abdul Djalal, Ulumul Qur'an. Surabaya: Dunia Ilmu, 2002. 
Adistia, dkk,Telaah Tafsir al-Thabari

Mohammad Aly Ash Shabuni, Pengantar study Al-Qur'ān. Terjemahan. Bandung, pt al ma'rif 1996.

Abi Ja'far Muhammad bin Jarir at-Thabari, Jamī' Al-Bayān An Ta'wïli Ay Al-Qur'ān. Jilid 8 